\title{
Analytical Hierarchy Process coupled with GIS for land management purposes: A decision-making application
}

\author{
$\underline{\text { D. Rojas }}^{\text {a }}$, J.C. Loubier ${ }^{\text {a }}$ \\ ${ }^{a}$ Applied Geographic Information Systems and Spatial Analysis Lab (GISLab), University of Applied \\ Sciences Western Switzerland (HES-SO) \\ Email:diego.rojas@hevs.ch
}

\begin{abstract}
This paper discusses the practical adaptation of a land-use planning methodology in Switzerland as a result of a combined usage of Geographic Information Systems (GIS) and a multiple criteria decision analysis (MCDA) method. The two approaches were integrated in order to help land managers to incorporate the impact of two land-use laws voted by citizens in 2012 and 2013 respectively. The direct democratic system in Switzerland allows citizens to participate actively in the decision-making processes in different fields of interest. In 2012 Swiss people voted in favor of limiting the construction of second homes, this initiative had as slogan "Ending the invasive construction of second homes". The purpose of the initiative is to protect citizens, heritage and the nature as well as the creation and maintenance of cities, habitats and liveable landscapes. According to the initiative, second homes cannot exceed 20 percent of the total community housing of a municipality. Currently this initiative is a federal law adopted by the national council and must be applied by all municipalities. Nevertheless, decision makers (DM) were not provided of an established methodology to determine and justify their choices before the citizens. Furthermore in 2013 Swiss citizens voted for another law on land-use which aims at limiting the size of the areas that will be built. According to this new rule building permit grants will be based on the foreseeable needs for the next fifteen years. In this context municipalities need to make decisions regarding two opposite objectives: How to respect environmental criteria while keeping in mind social-economic issues. Another important question arises: which are the most suitable areas that meet the new legal requirements? These most suitable areas will be freed up at the end of the process.
\end{abstract}

The main goal of our research was to develop a decision support methodology to help DM to make decisions objectively while minimizing the negative impacts of these choices in the Swiss canton of Valais. For example by identifying the most suitable hectares to be freed up through the zoning process. This was done by using a mathematical psychology method called Analytical Hierarchy Process (AHP) developed by Saaty (1977) which is based on ratio scales derived from pairwise comparisons in this case of spatial criteria. We developed a participatory process where DM and stakeholders with relevant knowledge chose seven spatial criteria. The number of spatial criteria were based on Miller (1956) research which suggested "the magical number seven, plus or minus two" which implies that humans can only process a limited amount of elements in information processes. An applicable solution provided by the integration of AHP and GIS in order to choose the location to be freed up is given by the minimum distance from the theoretical ideal. Thus when the distance from the ideal decreases the criteria are scored higher on the priority scale by the DM and when the distance increases from the ideal, those criteria are scored lower (Carver, 1991). The results were analysed on a GIS with the aim of creating a map series with the visual outcomes. In the first AHP session right before winter (November 2015) DM scored the spatial criteria "distance to the snow removal plan on the roads" was ranked as the most important with a weight of 40.2 percent. In the second AHP session in spring (April 2016) with exactly the same spatial criteria and the same participants the weight of this criteria was only 8.9 percent and was ranked on the fourth place. Other major differences were found among the two AHP sessions in winter and spring.

Results suggest that the timing of the decision-making process might have an impact on the preferences of spatial criteria. At the moment of the first AHP scoring process the city was deploying the snow removal plan. It appears that the relative importance of spatial criteria that are directly influenced by the weather conditions varies considerably if the scoring process is achieved in different seasons. At the end of both sessions in winter and spring respectively DM were satisfied with the two results and discussed openly about it arguing that every result represented their preferences at the moment of each workshop. Important differences were registered in the two AHP iterations so two different spatial scenarios were developed and DM decided to keep both of them. The final decision is currently discussed on a political scheme.

Keywords: Geo-governance, Analytical Hierarchy Process (AHP), Geographic Information Systems (GIS), decision making, multiple criteria decision analysis (MCDA) 
D. Rojas and J.C Loubier, Analytical Hierarchy Process coupled with GIS for land management purposes: A decision-making application.

\section{INTRODUCTION}

Land managers often need to make complex decisions in short period of times (Joerin et al. 2000). In the Swiss case DM needed to apply two constraining land-use laws with social, economic and environmental flavors. A second homes building limitation law and a land-use restriction law were introduced, however the application proved to be complex. The lack of a methodology for a decision-making process, to apply the laws and also an emotional debate represented a high risk exposure from a social and political perspective. Logically most of citizens wanted to benefit from the new law, therefore DM tried to get the least possible opposition from citizens, which is a phenomenon already discussed in the literature (vanLier, 1998). A participatory approach was needed to democratize the process among the stakeholders to apply the laws keeping in mind all the conflicting factors involved. This paper describes the methodology used to optimize the decision-making process through the usage of GIS and AHP combination in a participatory context. The goal was to solve a spatial allocation problem by finding the most suitable areas to be freed up through a zoning process.

\subsection{Second homes law voted in 2012}

Swiss citizens in 2012 voted for a restriction on the construction of second homes, the limitation was set by 20 percent of the total municipalities housing. This represents a major modification of spatial planning in tourist areas. In the Alpine regions, the economic, social, environmental and institutional challenges associated with second homes and the lacks of available land are numerous. In general these challenges can be characterized by the increase of urban sprawl, the decrease of overnight stays, the strong growth in land prices and the costs associated with the construction and maintenance of disproportionate public infrastructures in relation to actual use.

The phenomenon of second homes is worth reading in the light of a general trend towards peripheral urbanization. Indeed second homes are mainly coveted in the municipalities where the tourist facilities are concentrated. Low land prices and available building areas may also constitute a shifting demand for second homes in neighbouring municipalities. Similarly, a limitation of new second homes in tourist centers may lead to an overflow of the demand in neighbouring municipalities. Usually, peripheral municipalities have more inhabitants than jobs. The tendency towards dissociation between place of residence and workplace explains the behavior of many second homes owners, that as soon as they finish their work week go to the countryside to get some rest from the cities during the weekend. The concentration of jobs and the increase of the price per square meter in the center of the agglomerations and also the improvement of the transportation networks have helped to make this as a retreat strategy. The building limitation imposed by the new law has had its first effects, for example some municipalities ${ }^{1}$ had already exceeded the 20 percent threshold even before the law project was voted. This means that the demand decreased so the land price fell very quickly given the prohibition of building second homes.

\subsection{Law on land-use voted in 2013}

Additionally to the situation mentioned above, in 2013 Swiss citizens voted for the implementation of another law on land-use. This law proposes that the size of the zones to be built should be based on the foreseeable needs for the next fifteen years. By accepting this new spatial planning law, Swiss citizens showed their interest in the heritage and economic value of the landscape by their desire to reduce the oversized building zones. The reduction of building zones recommended by the law on land-use reinforces the transfer of constructions of second homes to neighbouring communes and even to more distant perimeters. Moreover the new law on landuse also includes the introduction of a 20 percent tax of the land value when the creation of new surfaces proves necessary, which means a third major modification on the policy of the development of the territory. Under this new legal frame land planners needed decision-making tools which would provide an objective assessment on the current situation and also be able to simulate future developments on the basis of changing framework conditions. All these factors are part of a complex spatial decision process which are commonly studied in the literature as a paradox of economic and conservation-oriented goals (Greene et al. 2011).

\section{LITERATURE REVIEW}

\subsection{Analytical Hierarchy Process}

There are several MCDA methods which are based on weight ponderation techniques however one of the most broadly used in different fields is the AHP an approach created by Saaty $(1977,1980)$. AHP was conceived

\footnotetext{
${ }^{1}$ For confidentiality reasons the name of the municipalities will not be named.
} 
D. Rojas and J.C Loubier, Analytical Hierarchy Process coupled with GIS for land management purposes: A decision-making application.

with the aim of developing a systematic method to define priorities and support complex decision-making processes through three main functions: structuring complexity, measurement, and synthesis (Forman and Gass 2001). This technique is based on mathematical psychology and works with fundamental elements of decision theory such as how to calculate scaling ratios of a set of choices according to importance. The author developed an approach which aims to build a hierarchical structure based on pairwise comparison of criteria relying on the judgments of experts (Saaty, 2008). Criteria can be organized in a hierarchical order according to the weight of ratios scales. The underlying fundaments of AHP is the ratio-scale theory developed by Stevens (1946). Even though Stevens' model had some problems and generated controversies (Graham, 1958), his classification of scales based on a ratio-scaling method has been considered one of the most important scientific measurement methods (Bernasconi et al. 2010). Its simplicity and power enable easy operational implementation. The criteria's coefficient weights are derived by calculating the eigenvector of a matrix of pairwise comparisons and the comparisons reflect the relative importance of two criteria in relation to the original objective.

The measurements derived from pairwise comparisons represent the relative strengths of preferences and feelings in a decision-making process. It is important to mention that the nature of subjectivity of judgment processes poses a major problem of inconsistency, as humans' preferences remain inconsistent and intransitive (Saaty, 1977). This concern has been largely discussed in the literature as the AHP comparison process is particularly difficult for humans when they need to estimate preferences on a ratio-scale basis especially with intangibles (Dyer, 1999). In his seminal paper Saaty (1977) discussed the inconsistency problem and proposed an indicator which enables to provide a consistency ratio verification to ensure that the pairwise comparisons are coherent by computing the consistency ratio. This verification process gives information on the degree of inconsistency among the pairwise comparisons, and if the consistency ratio goes beyond the threshold DM need to review their pairwise comparisons until the threshold is respected. This feature is very useful for real world applications, given that pairwise comparisons can be iterated until the suitable inconsistency ratio limit is reached, however the iteration process might be time consuming.

\subsection{Coupling Analytical Hierarchy Process method with GIS}

The relative ease of AHP facilitates its application with other techniques. It has been found that AHP usage is commonly coupled with other methods and it is not used alone. There is an important bibliographic review on the integrated usage of AHP with other techniques which was done by Steuer (2003) and Ho (2008). One of the approaches most used with AHP is mathematical programming, particularly techniques such as integer linear programming, mixed integer linear programming and goal programming. It is not within the scope of this paper to do an extensive literature review. There is a considerable amount of publications on the usage of MCDA and GIS combinations (Nyerges and Jankowski, 2010). Greene et al. (2011) developed a research on MCDA and GIS applications and listed the main factors that affect the choice and implementation of MCDA methods. The goal of using spatial solutions based on MDCA procedures is to facilitate the complex problem on multiple criteria location problem (MCLP). Malczewski and Ogryczak $(1995,1996)$ disserted on the MCLP and MDCA methods highlighting the strengths and weaknesses of these approaches. The first application of AHP integrated with a GIS was done by Rao et al. (1991) since then the coupled application of AHP and GIS became more frequent (Saaty \& Vargas 2012; Pourghasemi et al. 2012).

The usage of these two techniques together is very helpful when a multi-objective problem needs to be solved. Land planners face complex decision-making processes which frequently have two opposite goals that must be satisfied simultaneously: environmental balance and economic growth (vanLier, 1998). At the same time land planners are entitled to have the role as mediators in order to try to avoid objections, given that this is a compulsory requirement for the social acceptance of land planning procedures (Joerin et al. 2000). The integration of MCDA and GIS generally involves three fundamental concepts to solve multi-criteria problems: value scaling, criterion weighting and combination (decision) rule (Greene et al. 2011). MCDA methods are used in different cases with GIS, a first scenario can be a problem in which objectives are complementary. In these cases different objectives are weighted and combined with a simple addition (Voogd, 1983; Eastman, 2006). The second case the situation is more complex; the problem to be solved has conflicting objectives. In this kind of problems spatial units can be allocated according to a single goal although there are hybrid models that combines complementary and contradictory objectives. A possible solution in these cases is the allocation of priorities to the objectives (Rosenthal, 1985; Eastman, 2006). This allocation of priority processes can be carried out through the usage of AHP by mapping a suitability index based on the preferences of DM. 
D. Rojas and J.C Loubier, Analytical Hierarchy Process coupled with GIS for land management purposes: A decision-making application.

\section{METHODOLOGY}

The research emphasizes on the implementation of a global methodology based on a spatial approach to optimize the decision-making process to free up zones in municipalities in Switzerland. The process was carried out in different sessions where a continuing interaction between scientist and DM was accomplished through three workshops in the canton of Valais in Switzerland. DM and local stakeholders have different kinds of academic and professional backgrounds. Therefore a fundamental factor that was taking into account from the beginning of the process was the pedagogical aspect with the aim of avoiding any kind of fear due to the complexity perceived. This case study is a multiple objective problem which represents the first major functional framework that helped us to build a typology of decisions. For us the multiple objective context is given by the framework of the land-use law on second homes voted in 2012 and the revision of the law on spatial planning voted in 2013. The multiple criteria aspect of the approach relied on spatial analyses and mapping processes as instrument of geo-governance, for example to identify the most suitable hectares to be freed up (Rao et al. 1990, Voiron et al. 2009). The Figure 1 is a graphical representation of the conflicting objectives, in which there is a conflicting area that can be allocated only to one objective. However it is shown that two objectives are desired to be assigned in the same spatial unit. The first workshop took place the $21^{\text {th }}$ of May 2015 in which DM and stakeholders got instructions on the whole process (Figure 3) and specific information on the methodology. A critical step was to determine the spatial criteria which were going to be compared. To do this, we explained to the DM the combinatory characteristics of the AHP method, given that the amount of pairwise comparison depended on the number of criteria chosen, this is given by the combination equation:

$$
\left(\begin{array}{l}
n \\
k
\end{array}\right)=\frac{n !}{\mathrm{k} !(\mathrm{n}-\mathrm{k}) !}
$$

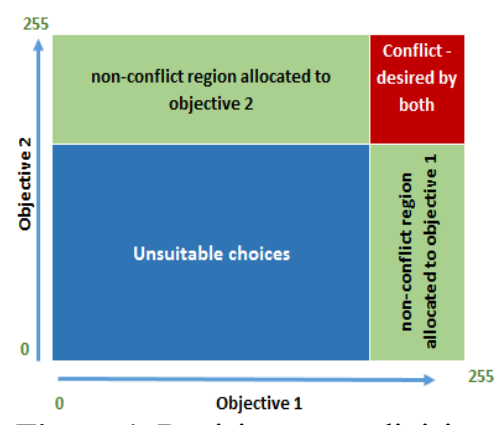

Figure 1. Decision space division. Source: (Eastman, 2006)

Therefore when $n$ (which represents the number of criteria) increases, the amount of comparison as well given that $\mathrm{k}=2$ which represents the pairwise comparisons approach. The AHP through the prioritization scale helped DM to determine which objectives where allocated to the spatial units of the municipality. The choice of the number of spatial criteria was also a critical element because DM had limited available time and it was difficult to get together the relevant people at the same time as they were incited to discuss the choices under a participatory environment. Another aspect of the combinatory characteristic of the AHP is the inconsistency. When the amount of criteria rises, the probability of inconsistency in the scoring process also increases because more comparisons must be performed. This is explained by the observed limitations of humans' capacity to process information (Saaty and Ozdemir, 2003). Hence the tradeoffs related to the amount of spatial criteria were explained with visual support as it is shown in the Figure 2. In the very

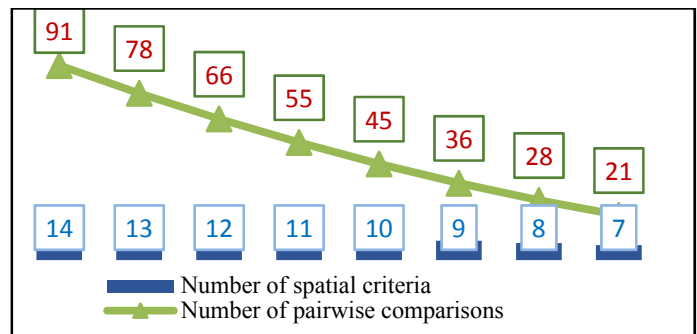

Figure 2. Decrease in the number of decisions based on the decrease in the amount of criteria taken into account. beginning fourteen criteria were chosen, this means that 91 of choices needed to be made. Nonetheless after discussions on the pertinence of the criteria, data availability and on our suggestions which were based on the literature only seven criteria were taken. This means that 21 pairwise comparison were made by the team. We highlighted the fact that human minds' capacity to process information is limited. Our argument relied on the research done by Miller (1956), which argued that humans can process a limited amount of elements and suggested "the magical number seven, plus or minus two" which means to keep the number of criteria comparisons between 5 and 9. In more recent research in the psychology field which is beyond the scope of this paper, the subject has created an academic debate ${ }^{2}$, nevertheless Saaty and Ozdemir (2003) concluded that

\footnotetext{
${ }^{2}$ Readers interested in the human capacity to process information are referred to Cowan (2001). He proposed to reduce Miller's number from seven to four.
} 
D. Rojas and J.C Loubier, Analytical Hierarchy Process coupled with GIS for land management purposes: A decision-making application.

“It appears that Miller's seven plus or minus two is indeed a limit, a channel capacity on our ability to process information". Then, taking into account previous scientific work plus the discussions in the workshop, DM took the criteria listed in the table 2.

After having chosen the spatial criteria a geographic data analysis was performed in order to validate that all the data was complete and in the desired format. A second workshop took place the $27^{\text {th }}$ of November 2015 in which the scoring of the criteria through the AHP method was done. The goal of this workshop was to find a best compromise solution to free up the best $\mathrm{X}$ hectares, then tradeoffs were expected. Based on the distance to the theoretical ideal (Carver, 1991) we proposed to the DM either to do the scoring process individually in a excel sheet programmed with the AHP or collectively in an open discussion on every spatial criteria. They decided to do the latter option and over an open dialogue every pairwise comparison were discussed and the scoring was set on a consensus basis. DM scored the spatial criteria through a pairwise comparison, relaying on the importance scale shown in the Table 1. The results were integrated in the software Idrisi in order to perform spatial analyses and the final maps were developed in the software ARCGIS. The third workshop was done the $1^{\text {st }}$ of

Table 1. AHP scale and its description, Saaty (1977)

\begin{tabular}{|c|c|c|}
\hline $\begin{array}{c}\text { Intensity of } \\
\text { importance }\end{array}$ & Definition & Explanation \\
\hline 1 & Equal importance & $\begin{array}{c}\text { Two activities contribute equally to } \\
\text { the objective }\end{array}$ \\
\hline 3 & $\begin{array}{c}\text { Weak importance of } \\
\text { one over another }\end{array}$ & $\begin{array}{c}\text { Experience and judgment slightly } \\
\text { favor one activity over another }\end{array}$ \\
\hline 5 & $\begin{array}{c}\text { Essential or strong } \\
\text { importance }\end{array}$ & $\begin{array}{c}\text { Experience and judgement strongly } \\
\text { favor one activity over another }\end{array}$ \\
\hline 9 & $\begin{array}{c}\text { Demonstrated } \\
\text { importance }\end{array}$ & $\begin{array}{c}\text { An activity is strongly favored and } \\
\text { its dominance is demonstrated in } \\
\text { practice }\end{array}$ \\
\hline $2,4,6,8$ & $\begin{array}{c}\text { Antermediate values } \\
\text { between the two } \\
\text { adjacent judgments }\end{array}$ & $\begin{array}{c}\text { The evidence favoring one activity } \\
\text { over another is of the highest } \\
\text { possible order of affirmation }\end{array}$ \\
\hline
\end{tabular}
April 2016, the results were presented and discussed through. By consensus, DM decided to iterate one more time the scoring process during the workshop given that it was found that the criteria "distance to snow removal plan" seemed to have a very high weight. Figure 3 shows the general framework of the process.

Timeline

1. First workshop with
DM and stakeholders
to establish the spatial
criteria to define the
zones to be freed up.

\begin{tabular}{|l|}
\hline 2. Geographic \\
database \\
construction based \\
on the criteria \\
proposed by DM \\
and stakeholders. \\
\hline
\end{tabular}

4. Spatial analysis based
on the criteria weights
and establishment of
maps with the most
suitable X hectares to be
freed up.

5. Third workshop with DM and stakeholders in order to provide the maps series with the results and iteration if needed.

Figure 3. Phases

of the process.

\section{SUMMARY OF RESULTS}

The first iteration of the AHP method, developed the $27^{\text {th }}$ of November 2017, is shown in the Table 2. The consistency ratio was 9 percent, which is the result of a high consensus level among the participants, but also of consistency in their choices. The criteria "Distance to snow removal plan" was ranked as the most important with a weight of 40.2 percent which was an unexpected result for DM. The following two criteria in the priority scale were "Land fragmentation" with 24.5 percent and "Distance to potable water supply" with 16.8 percent. The rest of the results shown in the table were under 20 percent, decreasing significantly from the fourth position

Table 2. First results of AHP scoring process.

\begin{tabular}{|c|c|c|c|}
\hline Spatial Criterias & Comments & Weight & Ranking \\
\hline 1 Slope gradient & & $3.8 \%$ & 5 \\
\hline 2 Distance to potable water supply & & $16.8 \%$ & 3 \\
\hline 3 Distance to the waste water system & & $8.9 \%$ & 4 \\
\hline 4 Distance to the snow removal plan & (on the roods) & $40.2 \%$ & 1 \\
\hline 5 Distance to urban areas & & $2.7 \%$ & 7 \\
\hline 6 Land fragmentation & & $24.5 \%$ & 2 \\
\hline 7 Distance to dangerous zones & & $3.1 \%$ & 6 \\
\hline
\end{tabular}
in the ranking. The integration of the results in the GIS allowed us to provide the overlay analyses of all spatial criteria in a single map (Figure 4). Every pixel has 23 square meters which is equivalent to a spatial unit. The colors of the pixels represent the score obtained through the AHP method, thus orange pixels got the highest scores which means that are the best spatial units to be freed up, respectively yellow and green pixels obtained lower scores. The preponderant weight of the criteria "Distance to snow removal plan" which was 40.2 percent, could have been induced by the timing when the workshop took place as the workshop took place right before 
D. Rojas and J.C Loubier, Analytical Hierarchy Process coupled with GIS for land management purposes: A decision-making application.

winter (the $27^{\text {th }}$ of November 2015). The deployment of the snow removal plan was already in motion and therefore it could have had an impact on the decision-making process. Because of this, we proposed DM to do a new iteration of the scoring process during the third workshop in spring (the $1^{\text {st }}$ of April 2016) and the results changed significantly as it is shown in the Table 3. The consistency ratio was 10 percent, however the weight of the criteria distance to snow removal plan went from 40.2 percent to only 9.6 percent, going from being the most important criteria to the fourth position in the ranking. The criteria "distance to the waste water system" went from 8.9 percent to 28.3 percent going from the fourth place in the ranking to the second place. This indicates that the distance to the potable water supply was almost two times more important than the distance to the

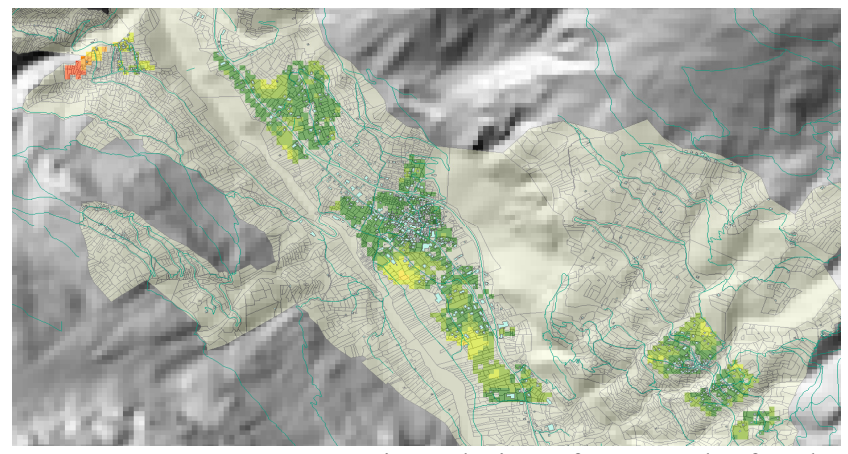

Figure 4. Best compromise solution of areas to be freed using GIS overlay analysis. waste water system before winter but the importance of the distance to the waste water system is slightly higher in spring. Land fragmentation score did not vary that much and stayed in the same ranking position.

Table 3. Results of the second iteration of the AHP scoring process

\begin{tabular}{|l|l|c|c|}
\hline Spatial Criterias & Comments & Weight & Ranking \\
\hline $\mathbf{1}$ Slope gradient & & $2.7 \%$ & 7 \\
$\mathbf{2}$ Distance to potable water supply & & $25.3 \%$ & 3 \\
$\mathbf{3}$ Distance to the waste water system & & $28.3 \%$ & 1 \\
$\mathbf{4}$ Distance to the snow removal plan & (on the roads) & $9.6 \%$ & 4 \\
$\mathbf{5}$ Distance to urban areas & & $4.6 \%$ & 5 \\
$\mathbf{6}$ Land fragmentation & & $25.9 \%$ & 2 \\
7 Distance to dangerous zones & & $3.7 \%$ & 6 \\
\hline
\end{tabular}

\section{DISCUSSION AND CONCLUSION}

It seems that the timing of the decision-making process might have an impact on the preferences of spatial criteria. When a spatial criteria is depending on seasonal factors as the weather conditions, it appears that the priority given to some spatial criteria might vary and rely on seasonal constraints. The current moment of the decision-making process seemed to be more important for DM than the future. Empirical research on human cognition in the field of psychology and neuroscience have revealed that decisions are mental processes involving both cognitive states such as beliefs and knowledge and affective states such as feelings and emotions $^{3}$ (Baddeley, 2010; Lempert and Phelps, 2014). In this study, the decision-making process has involved cognitive and affective states. Decisions were made on the basis of both quantifiable information about factual data and DM's preferences and feelings. The AHP method was used to quantify the relative strengths of the DM's preferences, therefore a cognitive and affective states were present in the process. The influence of environmental factors on the decision-making process has been studied in other fields such as behavioral finance as it was shown by Hirshleifer and Shumway (2013). This topic is an interesting subject for further research in which psychological aspects coupled with the concept of spatiality and environmental changes should be studied. In order to find a consensus between the seasonal results, we proposed to the DM to create several scenarios and overlay the spatial layers, and keep the spatial units which were systematically the best ranked in the scoring processes. Nevertheless, DM decided to keep the original results and discussions are currently in process mainly in a political context.

\section{ACKNOWLEDGMENTS}

The authors acknowledge the online AHP system implemented by Mr. Goepel, K. D. (2014). Rational decision making made easy, Singapore. http://bpmsg.com/academic/ahp, accessed the $23^{\text {rd }}$ of September 2015 . We are also grateful to our friend Ariel Cecchi for his helpful insights in the field of cognitive sciences.

3 "Cognitive" designates processes related to mental states such as beliefs, knowledge, intentions, expectations, and the like. "Affective" denotes processes concerning states such as emotions, feelings, moods, and other physiological states. 
D. Rojas and J.C Loubier, Analytical Hierarchy Process coupled with GIS for land management purposes: A decision-making application.

\section{REFERENCES}

Baddeley, M. (2010). Herding, social influence and economic decision-making: Socio-psychological and neuroscientific analyses. Philosophical Transactions of the Royal Society B: Biological Sciences 365(1538), 281-290.

Bernasconi, M., Choirat, C., and R., Seri (2010). The Analytic Hierarchy Process and the Theory of Measurement. Management Science [Internet]. (56), 699-711.

Carver, S.J. (1991). Integrating Multi-Criteria Evaluation with Geographical Information Systems. International Journal of Geographic Information System 5(3), 321-339.

Cowan, N. (2001). The magical number 4 in short-term memory: A reconsideration of mental storage capacity. Behavioral and Brain Sciences, (24), 87-185.

Dyer, J.S. (1999). Remarks on the Analytic Hierarchy Process. Management Science, 36, 249-258.

Eastman, J. R (2006). Idrisi Andes Guide to GIS and Image Processing. Clark Labs, Clark University.

Forman E, Gass S. (2001). The Analytic Hierarchy Process: An Exposition. Operations Research, 49:469-86.

Ho., W. (2008). Integrated Analytic Hierarchy Process and its Applications - A Literature Review. European Journal of Operational Research, 186(1), 211-228.

Joerin, F. Thériault, M. and A. Musy (2001). Using GIS and outranking multicriteria analysis for land-use suitability assessment. International Journal of Geographical Information Science, 15(2), 153-174,

vanLier, H. (1998). The role of land-use planning in sustainable rural systems. Landscape and Urban Planning, 41, 83-91.

Graham, C.H. (1958). Sensation and perception in an objective psychology. Psychological Review, 65, 65-76.

Greene, R., R. Devillers, J.E. Luther, and B.G Eddy (2011). GIS-based multiple-criteria decision analysis. Geography Compass, 5(6), 412-432.

Hirshleifer, D. and Shumway, T. (2003). Good day sunshine: stock returns and the weather. The Journal of Finance, 58, 1009-1032

Lempert, K. M. and E. A. Phelps. (2014). Neuroeconomics of emotion and decision-making. In P. W. Glimcher and E. Fehr (Eds.), Neuroeconomics: Decision-Making and the Brain (2nd ed.), Chapter 12. Elsevier.

Malczewski, J., and W. Ogryczak (1995). The multiple criteria location problem: 1. A generalized network model and the set of efficient solutions. Environment and Planning A, 27, 1931-1960.

Malczewski, J., and W. Ogryczak (1996). The multiple criteria location problem: 2. Preference-based techniques and interactive decision support. Environment and Planning A, 28, 69-98.

Miller, G. A. (1956). The magical number seven, plus or minus two: Some limits on our capacity for processing information. Psychological Review, 63 (2), 81-97.

Nyerges, T. L., and P. Jankowski (2010). Regional and urban GIS: a decision support approach. New York.

Pourghasemi, H.R., B. Pradhan, C. Gokceoglu, and K.D. Moezzi (2012). Landslide susceptibility mapping using a spatial multi criteria evaluation model at Haraz Watershed, Iran. In Terrigenous Mass Movements, 23-49, Springer Berlin Heidelberg.

Rao, M.S.V.C., S.V.C., Sastry, P.D. Yadar, K. Kharod, S.K. Pathan, P.S. Dhinwa, K.L. Majumdar, D. Sampat Kumar, V.N. Patkar, V.K. Phatak (1991). A weighted index model for urban suitability assessment a GIS approach. Bombay Metropolitan Regional Development Authority, Bombay.

Saaty, T.L. (1977). A scaling Method for Priorities in Hierarchical Structures. Journal of mathematical Pyschology, 15, 234-281.

Saaty, T.L. (1980). The Analytic Hierarchy Process. New York: McGraw-Hill.

Saaty, T.L., and Ozdemir, M.S. (2003). Why the Magic Number Seven Plus or Minus Two, Mathematical and Computer Modelling, (38), 233-244.

Saaty, T.L. (2008). Decision making with the analytic hierarchy process. International Journal of Services Sciences, 1, 83-98.

Saaty, T.L., and Vargas, L.G. (2012). How to Make a Decision. In Models, Methods, Concepts \& Applications of the Analytic Hierarchy Process (pp. 1-21). Springer US.

Rosenthal, R. E., (1985) Concepts, Theory and Techniques: Principals of Multi-objective Optimization. Decisions Sciences, 16(2), pp. 133-152.

Steuer, R.E. (2003). Multiple criteria decision making combined with finance: A categorized bibliographic study, European Journal of Operational Research, 150 (3) 496-515.

Stevens, S.S. (1946). On the theory of scales of measurement. Science, 103, 677-680.

Voiron, C., N. Dubus, J.C. Loubier, S. Liziard, (juin 2009). Evaluer les impacts du changement climatique sur le fonctionnement d'une aire urbaine littorale : outils d' 'aide a la réflexion et d'aide à la décision existants. 5th Urban Research Symposium on Cities and Climate Change World Bank-Marseille.

Voogd, H., (1983). Multicriteria Evaluation for Urban and Regional Planning. Pion, London. 